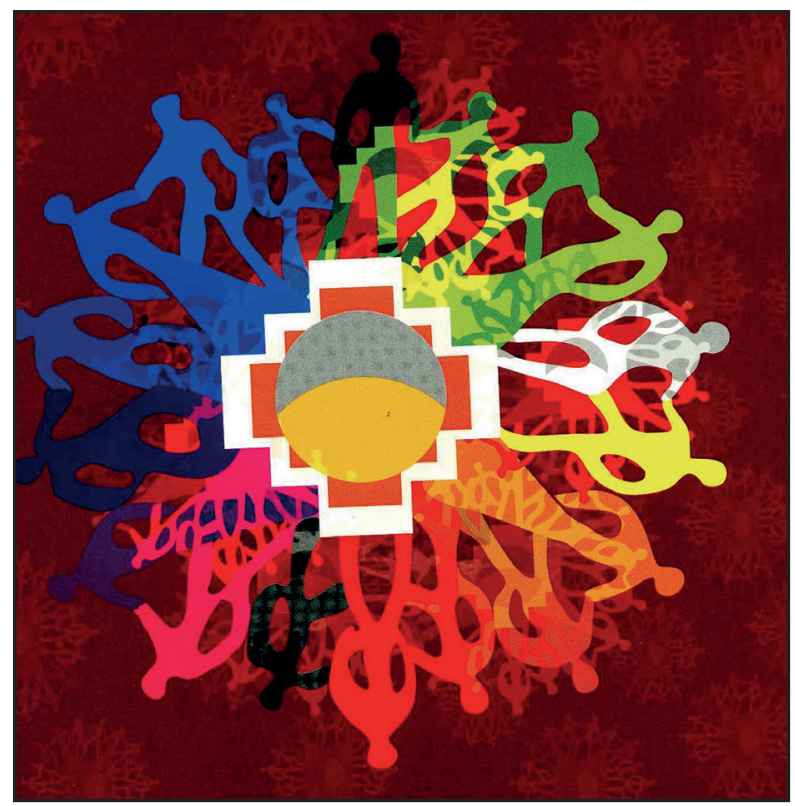

\title{
LA ESENCIA ANTAGÓNICA ENTRE EL DESARROLLO Y EL BUEN VIVIR
}

\author{
Andrade Polo, María Cecilia \\ Correspondencia: mceciandrade@gmail.com
}




\section{Resumen:}

Desarrollo y Buen Vivir son antagónicos. El desarrollo surge como estrategia capitalista para enfrentar una crisis sistémica en América Latina. Históricamente ha generado explotación, control político del continente y ecocidio. Su mayor fortaleza radica en que se convierte en ideología de control social.

El Sumak Alli Kausay corresponde a la cosmovisión kichwa, de cuidado, producción y reproducción de la vida del todo, en torno de la filialidad sagrada, con la tierra y la fraternidad entre todos los seres. Es una noción alternativa al desarrollo y al capitalismo. Por su principio filosófico relacional es convergente y abierto al encuentro intercultural con las filosofías y prácticas del Buen Vivir de otras culturas ancestrales de Abya Yala y del mundo y con las nuevas teorías y emprendimientos anti-sistémicos.

Palabras clave: Buen vivir, desarrollo, ecocidio, relacionalidad. 


\section{THE ANTAGONISTIC ESSENCE BETWEEN DEVELOPMENT AND THE GOOD LIVING}

Development and the concept of Good Living are antagonistic. Development emerges as a capitalist strategy to confront a systemic crisis in Latin America. Historically, it has generated exploitation, political control of the continent and ecocide. Its greatest strength lies in the fact that it becomes an ideology of social control.

The Sumak Alli Kausay reflects the kichwa cosmovision of care, production and reproduction of the life of the Whole, making reference to a sacred filial love with the earth and the sense of fraternity among all beings. It is an alternative notion to development and capitalism. In view of its philosophical relational principle, it is convergent and open to the intercultural encounter with the philosophies and practices of the Good Living concept of other ancestral cultures of Abya Yala and of the world, and with the new theories and anti-systemic ventures.

Keywords: Good living / Well being, development, ecocide, relacionalidad 


\section{Del desarrollo como estrategia de salida a una crisis estructural del capitalismo, al desarrollo como sustento de control sociocultural homogenizante}

Los años finales de la década de los cincuenta y los que iniciaron la década de los sesenta fueron años de particular importancia para los países neo-colonizados. Las revueltas y revoluciones que estos protagonizaron desafiaron en serio a los regímenes de los países dominantes.

Este histórico desafío obligó a que los regímenes dominantes crearan e instauraran políticas destinadas a asegurar su poder sobre los países neo-colonizados. Particular importancia en la aplicación de esta medida cobraron las situaciones de América Latina y África por la alta calidad revolucionaria de sus movilizaciones internas, que llegaron a constituir un hondo reto al sistema de dominio.

El empobrecimiento masivo de millones de seres humanos estaba garantizado por un sistema de poder criollo que tenía como cometido garantizar su control y represión. Se trataba de regímenes políticos criollos títeres, usualmente subordinados a poderes supra continentales.

La historia de esa época nos habla de grandes movilizaciones y contra-movilizaciones así como de acciones propiamente políticas, pero también educacionales, comunicacionales y militares. En medio de ellas las acciones eclesiales llegaron a cobrar una especial importancia dada la tradicional religiosidad de estos países 
y pueblos inmensamente ricos; pero sometidos al despojo y empobrecimiento.

Liberación, revolución y socialismo constituyeron la secuencia histórica en la que se inscribieron y aliaron llegando incluso a constituir un movimiento mundial con el liderazgo de la Revolución Cubana.

El desafío al poder estaba lanzado. En efecto, varios de estos países apostaron por procesos revolucionarios de liberación e incluso de socialismo, por lo cual el control continental estuvo en serio riesgo. Había que crear y operar algo que, siendo un cambio, en realidad no cambiara nada y asegurara el control. Ese algo constituyó el desarrollo.

No abrir paso a este cambio hubiese constituido no solo un riesgo mayúsculo para el control continental y de alcance mundial sino una pérdida de oportunidad de asegurar un mayor y mejor crecimiento de los alcances del sistema de dominio. Así entonces la salida desarrollista si bien obligaba por un lado a operar algunos cambios incómodos para el sistema, aseguraba por otro, el mantenimiento de su poder.

Había que escoger entre la pérdida del control continental y la operación de cambios para garantizar una mayor efectividad de su viabilización y ganancia. Enfrentar la maduración de procesos revolucionarios continentales y extra-continentales fue el mayor desafío para operar este cambio: la modernización obligada del sistema de producción para asegurar el sistema de dominio. Por eso es que la cruzada tuvo nombre y contenido anti-comunista mientras que la oferta alternativa era el desarrollo. 
Este proceso histórico sumamente expresivo y representativo ha marcado el destino de millones de seres humanos de este continente, sus culturas y su histórica búsqueda de mejores días para sus pueblos y sociedades. Los últimos años de los 50 y los iniciales años 60 constituyeron para nuestra América como dijera Martí, años decisivos, cuyos efectos le continúan influenciando mientras no exista un cambio revolucionario que le corresponda.

La obligatoriedad del cambio en la matriz de dominio no fue rápida ni de fácil viabilidad, pero había que hacerlo y se ejecutó no solo por vía de golpes de Estado, sino por el peso de la ideología al haber tenido que asumir el desarrollo como supuesta alternativa al empobrecimiento y al mismo tiempo como atajo al riesgo de una revolución comunista. Para ello se instrumentalizaron los sistemas confesionales religiosos y los sistemas educomunicativos.

Al grito creyente de "Viva Cristo Rey y abajo el comunismo", las inmensas y constantes marchas de alcance continental se sometieron al desarrollo y repudiaron el comunismo, desde luego sin dejar de lado la inmensa simpatía que para muchos sectores significó el proceso revolucionario de los llamados barbudos castristas cubanos.

Estos cambios obligados -como en este caso el desarrollo- siempre han sido una estrategia para no cambiar la esencia del sistema. Todas las sociedades humanas exigen modernizaciones, lo que constituye también desafíos para los sistemas de dominio.

Para el capitalismo - y para el capitalismo para países y continentes denominados "atrasados"- los cambios no se producen para modificar la esencia sino sus modos 
de operar su funcionamiento, cobrando así versatilidad y propiedad; más todavía cuando ha tenido que lidiar con identidades y culturas diversas. Es de anotar lo impresionante que resulta la plasticidad que muestran las modernizaciones capitalistas por más reaccionarias y formales que tuvieron que ser en su contenido. Desde luego, cabe también señalar las acciones verdaderamente criminales que formaron parte de esta campaña continental.

Así, en medio y como respuesta a esta realidad fue entonces como se forjó la categoría de subdesarrollo para calificar conceptual y políticamente a realidades, y a países de culturas no solo no modernas sino, no capitalistas. El resultado de esta contra revolución fue la imposición del desarrollo y más aún la recuperación del control continental, el tradicional "patio trasero" de los gringos.

Por ello es muy decisivo, para el efecto del dominio continental, no simplemente estar convencidos de la existencia de una condición de subdesarrollo sino estar ideologizados de que la utopía no era el comunismo sino el desarrollo. Pero esto no es únicamente un maquiavelismo político, es un puro asunto cultural que vertebra lo social y lo político, pues este territorio que ahora llamamos América Latina constituye un continente pluricultural, un continente asiento y símbolo de utopías, un continente de realidades mágicas -parafraseando a nuestro Gabriel García Márquez- y realidades sagradas, de identidades culto espirituales en donde no se entendió que no cabía ni como propuesta un socialismo sino varios, unos socialismos con contenidos espirituales y con interculturalidad, más bien un comunitarismo ni estatal ni burocrático, una socio comunidad de pluralidad de culturas, de géneros y generaciones. 
La avanzada más osada que hace el capitalismo y que se profundiza más aún con la globalización, es su versatilidad cultural en el sentido de una pluriculturalidad plástica bajo el reinado del mercado, subordinando a la naturaleza por su calidad ecocida, antropocéntrica y por el dominio y explotación de la fuerza del trabajo.

La condición cultural y no únicamente de clase, que asumió el capitalismo en su embate al supuesto atraso particularmente latinoamericano - a pesar de que en ese entonces se construía la comprensión de lo latinoamericano, limitadamente, sin hacer aún plena conciencia de lo indígena, lo negro y el mestizaje como partes fundamentales de su identidad- fue concebido como una situación a modificar, no solo para el logro de su particular versión de justicia social sino para impedir que ello derive en revolución socialista.

Muy pocose ha reflexionado sobre la avanzada en contra del denominado "atraso" de los países latinoamericanos como una de las justificaciones de las modernizaciones institucionales. Es importante señalar que en la exigencia de la reforma a institucionalizar obligatoriamente bajo el control del Estado también modernizado, la reforma del agro fue sustancial no solo en términos cuantitativos sino cualitativos, dado el peso comunitarista de sus culturas y el "atraso" -anti moderno- de la tenencia latifundiaria de la tierra y su sistema productivo.

Esto constituía en aquella coyuntura un bolsón de conflicto más urgente de lo que podría protagonizar la clase obrera. Los históricos levantamientos indígenas de los años noventa -particularmente en el Ecuador-confirman esta aseveración, realidad que obligó al advenimiento de 
sustanciales cambios en el Estado y sus gobiernos que operaron con reformas.

Resulta revelador el papel jugado por los partidos comunistas que apoyaron -y continúan haciéndolo- a gobiernos modificadores de la institucionalidad estatal como ente modernizador por vía desarrollista; pero no revolucionaria, desde su concepción etapista de una revolución. Esa misma misión cumplieron en esa época otros importantes entes, sectores sociales e instituciones públicas que se movieron entre una postura anticomunista, y una modernización necesaria. Una manifestación de lo dicho constituye la ruptura interna de la Iglesia Católica cuando unos grupos optaron por la defensa eclesial en tanto institución guardiana del orden, aliada del capitalismo y el desarrollo mientras otros forjaron una eclesialidad de liberación comprometida con los oprimidos, especialmente los campesinos e indígenas, cuyo papel fue determinante no solo en las luchas por la reforma agraria sino en su testimonio y compromiso revolucionario.

Resumiendo entonces, interpretando la realidad de esa época en América Latina, nos encontramos con una gran conflictividad situada más allá de una modernización institucional económica y socio política que bordea una realidad revolucionaria continental en la que el proceso cubano es su vanguardia y que, dada su trascendencia, el imperialismo tuvo que operar con una salida como fue el desarrollo. De esta manera y en medio de la gama de contradicciones de la época había también que encarar la contradicción entre reforma desarrollista y revolución.

El triunfo del desarrollo prometió cambios formales institucionales que poco servían a los sectores sociales tradicionalmente dominados y explotados. Más bien 
sirvieron de control y a la postre de reforzamiento del poder sobre estos. Puede decirse, entonces, que el desarrollo constituye una estrategia contra revolucionaria y una reforma del capitalismo para realidades como América Latina, y aplicada en situaciones de gran emergencia como la que vivió este continente durante los inicios de los años sesenta.

Es importante insistir que el dominio y la explotación son el fondo esencial del capitalismo y, su calidad antropocéntrica y ecocida, una necesaria consecuencia. Así, el desarrollo es una concreción política de la histórica y permanente estrategia de imposición de este sistema siempre que se enfrenta a situaciones de riesgo como fue la de los años sesenta en América Latina, lo cual no contradice el empleo de otras formas de violencia.

El sostenimiento del capitalismo exige sometimiento social, político económico y cultural. El manejo que el capitalismo hizo del desarrollo, sobrepasó la estrategia de superación de la crisis de los sesenta convirtiéndolo en valor cultural y en ideología de sostén de las estrategias que en adelante se han aplicado y se sigue haciendo para el mantenimiento remozado de este sistema, cuya naturaleza esencial es la acumulación y por ende un expansionismo que no se detiene ante ningún tipo de barrera. Para este cometido se desenterró la idea de progreso de la modernidad y se la asimiló al desarrollo. Es sumamente representativo que uno de los programas estrella del desarrollo anticomunista en América Latina, se haya llamado Alianza para el Progreso.

Es de destacar la fortaleza que ha alcanzado y viene alcanzando en nuestros países la palabra y concepto de desarrollo, elevado a la condición de ideología y propuesta 246 
como alternativa al neoliberalismo en el turno del poder con el que el dominio capitalista viene controlando a países y continentes.

La tipificación "tercermundista" y "sub-desarrollada" de varios países y vastos espacios sociales continúa presentándose como escenario apto para fortalecer el desarrollo. Su continuidad instituida a través de las versiones de desarrollo sustentable y desarrollo sostenible pretende ser una superación del desarrollo al que quieren readecuar y apuntalar. Pues sostener el capitalismo lleva indefectiblemente a terminar con el planeta, como materialidad hecha recurso de explotación y fuente de acumulación por la vía del mercado globalizado. Sustentar el desarrollo implica no sostener, sino debilitar la vida planetaria, lo que al mismo tiempo significa acabar o, funcionalizar a las culturas tradicionales y las nuevas culturas anti sistémicas, imponiendo una materialidad que les lleva a morir como tales y a quedarse sin su materialidad propia en la que es posible la vivencia de sus sentidos profundos. La supuesta renovación del desarrollo, como humano, sustentable y sostenible subsiste siendo, la alternativa para el mantenimiento del capitalismo, ahora globalizado. El desarrollo surgido en tanto alternativa para enfrentar el riesgo del advenimiento del socialismo, tiene ahora como cometido, enfrentar el riesgo de cualquier forma alternativa al desarrollo. Resulta entonces clave distinguir entre las alternativas de desarrollo y las alternativas al desarrollo.

Hay que reconocer y hacer conciencia de que es tal el éxito alcanzado por el desarrollo en materia de poder, que ha logrado asomar tanto como crítica al neoliberalismo, cuanto como alternativa post neoliberal, precisamente con el artificio de la sostenibilidad y la sustentabilidad. 
Evidenciado que el desarrollo se erigió como estrategia contra revolucionaria en los años 60 y que conceptual y políticamente es una salida resuelta e impuesta para impedir una alternativa radicalmente diferente al capitalismo, tampoco puede sostenerse como alternativa al subdesarrollo, ya que es su creación y ha sido condición de acumulación capitalista, aunque luego pase paradójicamente a ser una realidad a superar para seguir desarrollando y sosteniendo al capitalismo como tal.

El hecho de haber asumido al desarrollo como paradigma significa no conocer o negar el fondo filosófico, cognoscitivo y de organización económica, social y humana de las otras culturas, de nuestras culturas ancestrales, de las nuevas construcciones que conservan y adaptan su patrimonio cultural o de las que se levantan contestatarias y críticas al sistema, desde posturas ecologistas, de género, de generaciones, etc. Significa también que se ha mantenido limitada la posibilidad de elaborar y generar modelos alternativos, ya como recuperación, ya como creación.

La concepción del desarrollo parte de dar por sentado que el tiempo es lineal, progresivo y que se desarrolla, es decir que el futuro es superior porque supuestamente siempre está delante. Así se operó la mencionada asimilación de desarrollo a progreso. No hay referencias de que la idea de "progreso" haya existido por lo menos hasta antes del siglo XV, aunque a la mayoría de la gente por efecto del dominio le parezca natural, y viva convencida de que siempre estamos en proceso de mejoramiento, de acumulación, en lo económico en el conocimiento y en la vida misma. Esta idea de progreso es una ilusión. $\mathrm{Ni}$ los griegos en la antigüedad ni los cristianos medievales 
concibieron la idea de que en cada momento se mejora la condición de vida. Esta es una concepción del capitalismo moderno, surgida en el Renacimiento y consolidada como ideología en el s. XVI y XVII ${ }^{1}$ (Reascos)

La idea de progreso se contradice con otras comprensiones filosóficas, como la antigua dimensión temporal elaborada por la cultura andina por cuanto no necesariamente lo que viene" es superior ${ }^{2} \mathrm{o}$ es progreso, y el hecho de imponer que el capitalismo es futuro, nunca ha significado- progreso para muchas sociedades y pueblos del mundo. Esa generalización constituye prueba no sólo del dominio económico sino del control ideológico y la imposición cultural.

Las filosofías andinas indígenas no tienen una concepción lineal del tiempo: pasado, presente y futuro, sino cíclico - elíptica en donde lo evidentemente situado delante es el pasado que sirve de espejo en donde se proyecta lo vivido como orientación para el accionar. El dominio de la idea del progreso no la desaparece del todo, sus fundamentos se continúan y recrean como resistencia; sin embargo se generan rupturas en el proceso interno de esas culturas, lo que se facilita convergentemente con la realidad de empobrecimiento general de su actual calidad de vida, producto de la explotación, opresión y discrimen por parte de la sociedad colonial, de la sociedad republicana "nacional", y de la sociedad "desarrollada" y "progresista",

1 REASCOS Nelson, Reproducción de Apuntes de Conferencia dictada en la Universidad Católica de Quito., EECA, Guaranda, 2000

2 "La crítica está dirigida a la concepción de la historia como una necesaria sucesión de edades obligatorias en un movimiento de evolución de lo inferior a lo superior" en CÁCERES, Milton, El Gran Poder de la Palabra Desarrollo. 
fortalecida con la integración masiva de pueblos y culturas en la globalización.

Una perversa lectura sobre la consideración que al pasado dan las culturas indígenas ha servido para pronunciar una condena de atraso por un pretendido culto al pasado de estos pueblos, volviendo objetivo estratégico el operar una modernización a su interior por parte del Estado, la universidad, las ciencias sociales, e inclusive las iglesias comprometidas con transformaciones sociales y grandes sectores de la izquierda influenciada por el pensamiento occidental, aunque desde una óptica revolucionaria, también suscribían la ideología del progreso y aún no lograban cuestionar el antropocentrismo.

\section{Consideraciones sobre las diversas formas de buen vivir como alternativas al desarrollo}

Luego de haber reflexionado sobre el desarrollo, la ideología del progreso, y el capitalismo como sistema en sus persistentes remozamientos y expansiones, que sin embargo no modifican su esencia estructural y de sentido, puedo concluir que ello es un MAL VIVIR.

Históricamente y para que se produzca acumulación de capital, tiene que existir explotación de mano de obra y destrucción de la naturaleza, hechos que llevan a una pérdida de sentido de VIVIR, porque se acumula sentido de muerte, pero no como parte de un proceso natural sino como resultado de una violación y ruptura de la relacionalidad sagrada de todos los seres por medio de la imposición de una calidad de devoración y de dominio como condición de existencia de ese sistema. 
Este mal vivir, ante la evidencia de que la acumulación voraz y desenfrenada, produce conflictos, atropellos, y batallas incesantes entre los seres humanos, las culturas, las sociedades y por otra parte genera ansiedad, y angustia por la ambición y por las carencias de condiciones materiales de existencia, o por temor de perderlas, con miedo de la inseguridad de la vida, en permanente competencia y desasosiego, y más aún en persistente olvido e inconciencia del sentido natural de lo humano, y de la conexión relacional con la vida de los otros, de lo otro, de la VIDA misma.

Las sociedades y los seres humanos como efecto del desarrollo están enfermos de estrés, vulnerables y sometidos a las producciones del mercado de valores, de gustos, de enfermedades, de sentidos que las alejan de la condición humana natural. Las culturas se deterioran, se disminuyen y se pierden en este dominio que les mata, al privarles de las condiciones materiales, que son el territorio de su cultivo y reproducción.

Sin embargo, es también este mal estar, efecto del mal vivir, esta impugnación de la artificialidad de la vida, lo que crecientemente nos lleva a buscar otros confines de sentido, nos obliga a evolucionar con nuevas creaciones. Así, una de las fuentes más fecundas y pertinentes son precisamente los saberes, experiencias y vivencias de las construcciones de las culturas, no sólo invisibilizadas, sino sobre todo abandonadas y como queda dicho, desperdiciadas como fuentes de conocimiento y principio propositivo de nuevas creaciones y construcciones de cómo caminar en la producción y reproducción de la vida, dando respuesta a los actuales desafíos humano 
civilizatorios, que al mismo tiempo constituyen una invitación que no se puede ignorar ni malograr para la recuperación, regeneración y recreación de las culturas y de la propia condición humana correspondiente con ello.

Esta comprensión remite al absurdo de haber desconsiderado, olvidado y más aún desperdiciado las múltiples posibilidades de otro "desarrollo" y de otros desarrollos de la gran diversidad de culturas que como las andinas basan su existencia en una relacionalidad diferente entre seres que, siendo distintos, requieren complementarse, no dominarse.

Se requiere entonces apreciar estas múltiples posibilidades de otros desarrollos, tanto desde una conciencia del propio instinto de conservación y conexión relacional natural e intangible con el todo, cuanto desde la reflexión racional, crítica y responsable con la vida.

Cada modo de despliegue de la vida humana social tiene que ver con la concepción filosófica del mundo, con el sentido mismo de la existencia, que es lo que dirige y se expresa en la manera de producir modos de desarrollo propios, correspondientes, a los que convencionalmente prefiero referirme como despliegue 0 como otros desarrollos, para remarcar la distinción con el modelo de desarrollo estratégicamente impuesto en la economía y la cultura, para la expansión e inclusión del capitalismo en los países llamados -como parte de esa estrategia- "tercer mundo", "países subdesarrollados o en vías del desarrollo".

Hay innumerables maneras y caminos para organizar el movimiento de la vida social y su reproducción correspondientemente con la diversidad de las culturas 
que lo producen, distintas del "desarrollo" y sus principios. En medio de esta gran diversidad el elemento o principio matriz del desarrollo capitalista moderno y sus remozamientos históricos que es producir para acumular y todas las consecuencias que de ahí se derivan, se diferencia radicalmente de estos otros desarrollos o maneras de despliegue, que se revelan como variantes de cuidado de la vida.

Si bien la explotación económica y la defensa de la vida planetaria ubica la obligatoriedad de acabar con el sistema que las sostiene, la condición cultural ubica la búsqueda de coherencia con los sentidos cósmico filosóficos que orientan el vivir, o mejor los vivires que también están amenazados. Al mismo tiempo estos nos muestran a quién volver la mirada, brindando perspectivas y elementos para nuevas construcciones de calidad integral de vida.

Al desarrollo como mal vivir habría como oponerle no sólo un único modelo de buen vivir, sino tantos diversos vivires -como diversas culturas nuevas y viejas distintas de las generadas por el desarrollo del capitalismoexisten. Hablar de buen vivir sin embargo implica no sólo la recuperación de las maneras de vivir de culturas no capitalistas, sino también una apreciación de los valores de estas, sin caer en ningún tipo de fundamentalismo cultural, y más bien desde reconocer que las culturas al ser vivas y dinámicas, tienen momentos de auge $y$ también de deterioro y destrucción, que están cruzadas de contradicciones, y que algunas han tenido en determinado momento histórico que sobrevivir en convivencia con el capitalismo, ya diluyéndose en el sistema, ya perdiendo valores, ya en yuxtaposición o sincretismo, ya resistiendo y regenerándose. Desde mi comprensión, un buen vivir, 
por diverso que sea, tiene que ver con el cuidado de la vida y su reproducción, con el cuidado de la vida de todo y de todos, vale decir del TODO.

Además de las alternativas de pueblos y culturas ancestrales puede haber nuevas propuestas alternativas al desarrollo y de hecho hay muchas en las que prevalecen distintos aspectos. Nombraré como muestra algunas corrientes actuales: unas que priorizan la calidad de las relaciones sociales como por ejemplo las propuestas de economía social y solidaria. Otras, como las corrientes ecologistas que ponen el énfasis en el mantenimiento y conservación de la naturaleza, lo que implica no poner en riesgo su equilibrio, negando la acumulación voraz e insaciable que exige el capitalismo y su cultura. Existen propuestas que plantean serias rupturas en el manejo de la economía como es el caso de la Teoría del Decrecimiento, o el Crecimiento Cero. Por otro lado están aquellas como la Ética del Cuidado que se oponen a la acumulación capitalista y la destrucción planetaria, porque ubican el cuidado de la naturaleza, del ser humano y de la sociedad como el sentido fundamental y la actitud ética de vivir. También están las corrientes eco-feministas que critican la alianza del capitalismo y el patriarcado, proponiendo relaciones horizontales entre los géneros y en general, relaciones armónicas, priorizando la preocupación por la familia, coincidiendo en mucho con las culturas más ligadas a la tierra.

La construcción de alternativas al desarrollo implica que sin dejar de lado las condiciones de dominio y explotación que muchas sociedades continúan viviendo como efecto de la condición de clase, es necesario también - en el sentido de construir una salida completa y compleja para 
el ser humano de nuestros países- plantearnos salidas culturales. De otra manera no podríamos conocernos plenamente, ni trazar un camino apropiado de liberación.

Inmensos conglomerados humanos sociales y culturales yacen bajo la explotación de clase e inmensos conglomerados del mundo y de América Latina viven despreciando valores, saberes y sentidos de vida que pueden ser alternativos a todo dominio. Existen sin embargo grupos que todavía practican vivencialmente sus antiguas tradiciones culturales y otros nuevos que ya viven practicando alternativas creativas de resistencia.

Aunque falta mucho por conocer es necesario al menos dejar señalado que las culturas de oriente, y las africanas ancestrales, también tienen una visión sagrada del cosmos, una filosofía de relacionalidad cósmica integral, lejana de la idea de acumulación individual lo que hace que también sean espacios de riqueza por aprender y recuperar como otras versiones para "otros desarrollos" coincidentes con las ideas del buen vivir de Abya Yala y particularmente con el sumak kausay andino.

\section{Nociones de buen vivir desde Abya Yala}

Abya Yala, el nombre que los Kuna le dieron al continente que los peninsulares se acostumbraron a llamarle "las tierras de Don Américo", expresa una "existencia extensa, solemne y en plena madurez". Las tierras de Abya Yala constituyen una base garante que por su generosidad, incentiva, propende y exige de los humanos una devolución en la medida de un existir integral y generoso que es la calidad cultural de tales. 
Una tierra extensa, solemne y en plena madurez no solo garantiza sino exige vivirla bien. Lograr una vida plena, una vida bella, de plena madurez y solemnidad es la ética condición que se puede y debe lograr -incluso como exigencia de los mayores- como una condición para alcanzar la inmortalidad.

La noción de buen vivir, o sumak alli kausay en lengua quichua, tiene una afinidad profunda con los mundos filosófico vitales de otros de los cientos de pueblos y culturas de Abya Yala, y todas corresponden a concepciones ético, políticas y espirituales que al mismo tiempo que exigen caminar, ayudan, dirigen y permiten llegar al sentido del buen vivir, aportando con invalorables particularidades que convergen y se complementan para una propuesta de cuidado y reproducción de la vida armónica entre los seres, que profetiza, desafía y propone vivir alternativamente al impuesto desarrollo.

Haré referencia breve a algunas de ellas, como un intento de advertir la prodigalidad y fecundidad de sus sentidos, para romper en algo las limitaciones de traducción y percibir la profundidad de lo que se logra con la traducción de buen vivir.

Así de' aaye paa ye expresa para los siona secoya, el buen vivir, y significa reflejar en el cuerpo los colores de la naturaleza, es decir una vida integrada como totalidad, es decir como producción y cuidado de la comunidad de seres, en donde el ser humano es uno de aquellos.

Los guaraníes y su: "iviy mara ey" que expresa el mandato ético de caminar erguido para alcanzar la Tierra 
Sin Mal, que para ellos era un lugar donde, "sin pasar por la prueba de la muerte se podía llegar en cuerpo y alma", lo que implica un comportamiento profundamente recto, y amoroso no separado de la naturaleza y en unidad con la comunidad.

El sumak qamaña de los aymaras expresa el mandato de vivir en armonía con los ciclos de la madre tierra y en hermandad y comunidad compartiendo sin competir en una convivencia construida por el consenso entre todos. (Huanacuni Mamani 2010).

Pueblos del norte de la Amazonía tienen como dirección de su vivir "volver a la maloka" lo que significa volver al cosmos y a uno mismo como referente, en tanto la maloka está en cada ser y en el cosmos lo que lleva a entenderse como uno con el cosmos y relacionarse armoniosamente, con este que es la fuente de sabiduría.

Los mapuche expresan la misma idea de buen vivir como ixo fij mogen en su lengua, y los aymara de Bolivia lo expresan como ñan dereko.

Los términos con que los pueblos ancestrales expresan sus sentidos de vivir, de desenvolverse, de desarrollar su vida, son diametralmente lejanos a los parámetros del desarrollo y no ameritan una simple traducción, sino una comprensión de su diferente calidad de entender y de vivir dando cuenta de una exigencia ética del ser humano, en conexión íntima con los otros humanos y el resto de la naturaleza, lo que hace que la comunidad sea una forma vital y natural de ser y de existir. 


\section{El sumak alli kawsay}

Hablando desde los Andes reflexionaré sobre el buen vivir kichwa: sumak alli kausay como componente esencial de la visión cósmica de esa cultura. Las nociones de nuestras culturas ancestrales constituyen un tejido compuesto de trama y urdimbre, complejidad en la que sus partes resultan indispensables para la existencia del conjunto del sistema vital.

La vida o kausay, en el mundo andino kichwa es un continuum relacional de seres. La relacionalidad es el principio central organizador de la vida, que se concreta en tres principios más: la correspondencia, la complementariedad y la reciprocidad. Con ellos se organiza la vivencia en esta comunidad de seres como un todo. Para la pluralidad de las culturas andinas, la vida y su reproducción es asumida como comunidad y una comunidad es una entidad no únicamente humana, sino integral, integrada, integradora de todos los seres de la naturaleza, y de los cuatro elementos primordiales que en su visión cósmica los conforman: tierra, aire, agua y fuego. Así el sumak alli kausay, para la cultura andina, y en particular para la cultura kichwa, expresa un modo comunitario, íntegro y holístico de vida; pero todo en torno de un sentido filial, agradecido, retributivo y festivo de ser, como individuo en comunidad.

La ausencia de antropocentrismo hace que su sentido comunitario que incluye al conjunto de seres y elementos sea lo esencial. Es esta índole de relacionalidad comunitaria la clave para la calidad de vida y de reproducción. Así un antropocentrismo sería soledad, frío y pobreza... pero a la 
vez una expresión de decadencia como de hecho sucede con cualquier cultura y sociedad humana.

En el mundo kichwa todos los seres tienen samay (espíritu, fuerza de energía vital). Esto les confiere sacralidad, calidad de existencia que debe ser reverenciada, agradecida y reciprocada porque ello alimenta el samay.

Si la vida o kausay es un continuum relacional, es decir comunitario, entonces la calidad sumak alli hace referencia a este contenido y resultado de las relaciones de complementariedad, correspondencia y reciprocidad. Esta calidad sumak alli, que como traducción al español puede sonar a redundancia, debe entenderse en su complejidad. Alli se traduce como bueno y sumak también significa bueno, pero en el sentido de maravilloso, sublime, bello. Por tanto sumak alli kausay es un modo, un orden de la vida, que deviene de una vivencialidad e interpretación del carácter de un todo relacional, integrado y dador, de calidad maternal que le confiere la condición de sagrado y que en lengua kichwa es pachamama.

La correspondencia de los elementos de la pachamama hace referencia al orden natural de la vida y explica que cada uno tiene su sitio, su lugar y su espacio en donde se corresponde y corresponde tanto en lo individual y en lo comunitario, entre los seres y los elementos de la naturaleza, entre lo de arriba y lo de abajo, entre la vida y la muerte, entre la siembra y la cosecha, entre el trabajo y el descanso. No se trata de un equilibrio mecánico, sino de un movimiento dinámico y cíclico, en donde el pasado se vuelve futuro en tanto espejo que orienta las construcciones del presente. 
La complementariedad significa que todo ser no existe sino acompañado con su complemento. El movimiento de la vida ocurre en ligazón indisoluble que se completan y completan a otros. Todo existe con y como complemento, así se confiere sentido comunitario.

La reciprocidad es una cualidad vital que mantiene varias armonías. "...a cada acto corresponde, como contribución complementaria, un acto recíproco" (Estermann, 2006, 139). Este principio funciona tanto en las relaciones entre humanos cuanto en las acciones y relaciones, con la naturaleza y con lo humano y la naturaleza. La reciprocidad kichwa es un comportamiento que deviene de un orden del Cosmos. Dar en esta cosmovisión es un comportamiento ético natural, que da inicio a un constante y permanente flujo entre dar y recibir, en donde dar es tan natural y tan deber como recibir.

Esta manera relacional de vivir guarda similitud con otras culturas ancestrales. En lo que se refiere a la cultura ichwa está afianzada y vivificada por la noción de pachamama que cruza su visión cósmica y que se refiere - como anoté- al tiempo y espacio concebido como madre. Así entonces los seres andinos están protegidos y a su vez comprometidos con el todo maternal que cuida, provee, y devuelve con magna generosidad.

La comprensión relacional y comunitaria de todos los seres hace que sean y se entiendan y sientan como parte de ese todo maternal en la medida de la reciprocidad, la correspondencia y la complementariedad en donde al no existir ni soledad ni aislamiento, se reproduce el sentido vital comunitario. Así, la existencia se entiende como coexistencia, como compartir y como devolución o pago 
pues solo así se garantiza la reproducción de un modo de producción comunitario de la vida.

Este entendido comunitario vital y vitalizador está representado en el trazo cosmogónico del Koricancha, en donde el cosmos, esa totalidad maternal es una casa. Una casa en donde todo vive y se reproduce en relacionalidad, correspondencia, complementariedad y reciprocidad. Nada queda fuera de la casa, ni aislado de la relacioanlidad sagrada, ni existe separado de su complemento, ni un estar al margen del orden de correspondencia de tiempo y espacio.

El cosmos se representa en la casa, dentro de la cual todo tiene vida y tiene Samay (espíritu). El óvalo representa pachak yachachi (tiempo y espacio). En el centro la chakana (puente), expresa la relacionalidad en el tiempo y en el espacio. Los elementos ubicados en ambos lados de la casa, cada uno enfrente de su complemento: sol y luna, chakra y árbol, hombre y mujer, lluvia y granizo, estrellas de verano y nubes de invierno, por señalar algunos ejemplos. Los tres segmentos superior, central y de la base de la casa muestran la unidad y correspondencia de estas tres dimensiones del espacio-tiempo: hanann pacha, kay acha y ucu acha. La reciprocidad queda incorporada en la natural obligatoriedad de dar y recibir como la garantía del cuidado y reproducción de la vida de cada uno y de todos; lo que a su vez implica la reproducción de la vida de la casa, es decir del todo. 


\section{Koricancha}

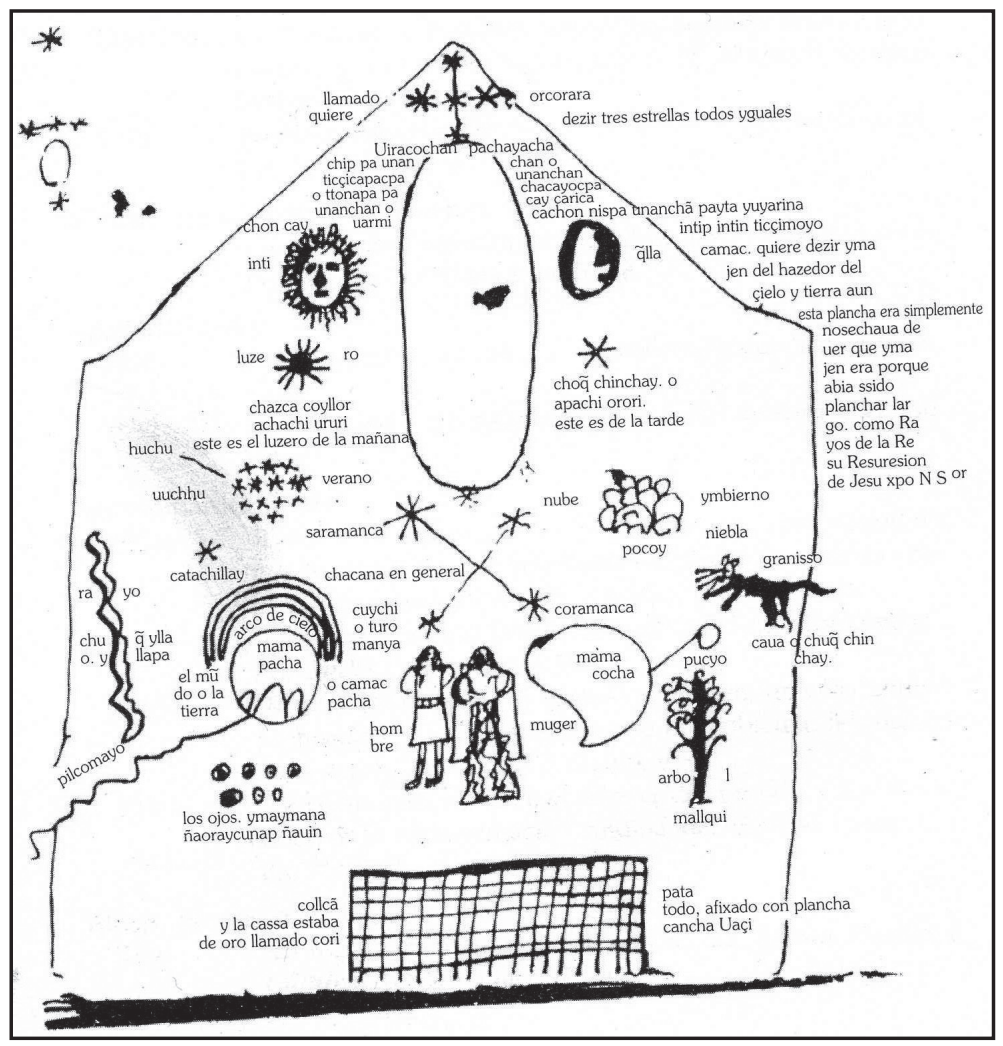

Dibujo del siglo XVI, Juan Santa Cruz Pachacuti Yamqui Salcamayhua

El modo relacional en que se organiza el cuidado -producción y reproducción- de la vida en la casa constituye el sumak alli kausay. El buen vivir kichwa se constituye como convivencia comunitaria de seres diferentes que accionan en minga, para cuidar, mantener, producir y reproducir la vida de la casa. 
Vivir dentro de esa casa-cosmos implica hacerlo cumpliendo como un deber cuidar la vida del TODO. En comunidad de sumak alli kausay, el ser humano convive con animales, tierras, plantas, y todos los seres en un permanente flujo de dar y recibir. Grillo y Rengifo expresan esto como "criar y dejarse criar". (Grillo Eduardo. Cit. Andrade: 2004).

El runa es el ser humano correspondiente con esta ética. El runa, que se construye como parte de la comunidad, como resultado de estar en ella y al mismo tiempo por su propia naturaleza es un edificador de comunidad pero no es un ente superior.

Alser, como queda señalado, el SUMAK ALLI KAUSAY, un orden sagrado, un modo integral de vivir que organiza la vida en todos sus aspectos, no sería pertinente segregar lo económico, lo ambiental con respecto a la organización social, política, espiritual y religiosa.

Retomando de Cáceres la idea de recuperar el vocablo OIKOS que significa CASA y que se traduce ECO en la raíz de economía y ecología (Cáceres 2011), un vivir bien o un sumak alli kausay, es un desenvolvimiento, un despliegue, un desarrollo OTRO, que es totalmente antagónico con el desarrollo cuyo sentido es comprender y manejar la economía como acumulación para el mercado, lo que implica romper las relaciones entre los seres humanos y con los otros seres de la casa, destruir a los habitantes de la casa y acabar con la propia casa. Lo que en el nivel espiritual de estos pueblos implica profanar la casa cosmos, que es asumido como madre. 
El sumak kausay es un camino y una creación y resultado, producto colectivo, vivencial, histórico. No es creación de determinado individuo, intelectual o personalidad sobresaliente. Los itos, y en este caso, valor y valoración de sentidos vitales y vitalizantes son patrimonio colectivo que configuran ese auto mandato, esa vigilancia como también un camino para ser y una muestra como resultado de ese ser. Por tanto es algo que se ha vivido, y que por tanto puede ser una propuesta orientadora de creaciones alternativas.

La producción en esta calidad de ivir deviene de la armonización del tiempo con el espacio por ello es que no puede ser agresiva ni con los seres humanos ni con los otros seres naturales. Esta Comunidad constituye la unidad productiva esencial y sus relaciones se corresponden desde el sentido del dar y el recibir. Así la minka es un modo de trabajo fundamental junto a otras formas recíprocas como el cambia mano. La distribución también ha sido hecha a partir de las necesidades del cuidado de la vida de los seres de la comunidad.

En este modo de vida pierde todo sentido la apropiación del trabajo del otro. El ahorro no existe como se entiende en Occidente. En la economía de sumak alli kausay se guarda una reserva de productos para el respaldo de la vida en tiempos de escasez y acorde con las regulaciones naturales de trabajo y descanso de la tierra de los runas, pero no se lo hace desde el interés de acumular. Así por ejemplo hay instituciones como el priostazgo, que consiste en elegir priostes a los miembros de la comunidad que les ha ido bien en la cosecha, y han podido acumular en ese año, para que costeen los gastos de las fiestas comunitarias, lo cual es motivo de prestigio social, generándose así un 
proceso de redistribución que cohesiona a la comunidad e impide la acumulación privada.

La chakra es un espacio-tiempo cultural agrícola armónico que evidencia que la filialidad humana con la naturaleza es indispensable para el mantenimiento de la vida. Cáceres afirma que los procesos chakra son espaciotiempos verdaderamente sostenibles, "fractales que relacionan los sistemas económicos con los ecológicos" (Cáceres: 2011). A lo que debemos añadir los sentidos espirituales de sacralidad del conjunto de la vida.

Considerando el carácter histórico y dinámico de las culturas y las sociedades hemos de señalar que la propuesta sumak alli kausay corresponde a un momento de auge cultural de nuestros pueblo- culturas ancestrales. Hay muchos elementos del sumak kausay que perviven como forma de resistencia o yuxtapuestos, sincronizados o enclavados en espacios comunitarios. Muchos se han recreado y se los puede encontrar como prácticas vivas en campesinas e inclusive urbanas. Hay expresiones de ello también en la vida de comunidades migrantes fuera del continente.

He de insistir en lo propuesto en la primera parte, en cuanto a los efectos del desarrollo y de los sistemas de explotación. Siendo racista y etnocentrista, el capitalismo no puede abandonar su condición de dominio y racismo dado que uno de los baluartes identitarios de su seguridad es su pretensión de supremacía cultural, económica, social y política. Sin embargo opera con tal plasticidad que le hace un sistema económico, social, político y cultural que siendo duro, adaptable, versátil, pero no para abrirse a otras culturas en una relación intercultural menos a un 
desarrollo "otro", es decir, que considere la vida desde los sentidos y valores de las culturas diversas como soberanas porque no puede renunciar a su condición de dominio etnocéntrico encaminado a la acumulación privada.

Sinembargo, elcapitalismooccidentalizadoryunicultural ha tenido la osadía de incluir en el mercado valores y creaciones propias de un sistema alli kausay, vaciándolas de su contenido atrapando sus símbolos y buscando como agazaparlas y adaptarlas funcionalizándolas al sistema. Pero más grave aún es el riesgo de que los Estados las utilicen para remozar su dominio, creando nuevos nombres desde y, para el mismo desarrollo.

Para concluir quiero señalar que la noción sumak alli kausay es una utopía porque imagina y proyecta la existencia del Runa como su sujeto y producto, pero es una topía en la medida en que logra que esos seres continúan construyendo culturas como cultivos de seres concretos y existentes que viven y conviven de manera y calidad de buen vivir. Por eso las nociones ético, políticas y religiosas de sumak alli kausay constituyen proyectos utópicos en donde sus protagonistas buscan un futuro de plenitud feliz.

Para algunos investigadores esto constituye una utopía, es decir algo a lo que se podría llegar, pero que no se logra. Desde mi punto de vista, una noción ética es algo que se alcanza a medida que se lo busca, que se vivencia. Deja entonces de ser algo para tener algún día y pasa a ser algo a construir permanente y cotidianamente, porque es la vivencia testimonial de buen vivir en sus variantes culturales, lo que hace posible saber-ser-tener esa utopíatopía. 
Abya Yala, esa tierra en plena producción, tiene sentido en la medida de su utopismo como gran proyecto y, en la medida de su posibilitación a través de su buen vivir.

Un buen vivir sin un faro guía de calidad utópica estaría condenado a no tener sentido, a no existir. Precisamente lo que le guía impidiendo su no-existencia, es la calidad utópica. Y es esta exigencia aparentemente inalcanzable lo que hace que la pluralidad de nociones de buen vivir en Abya Yala, tenga sentido vital, vitalizante y cualificador, que lindando con lo sagrado es al mismo tiempo un trabajo humano debido.

La noción sumak alli kausay y sus variantes culturales constituyen patrimonio de todos los pueblos y culturas de Abya Yala/América. Tiene hoy un sentido que habiéndolo recuperado y rescatado constituye una noción básica, apropiada y realmente alternativa para la construcción de recuperación de sentidos nuevos y renovantes de vida en el camino para alcanzar la Tierra Sin Mal.

Quizá entonces la revolución que nos corresponde, tenga hundidas sus raíces en estas antiguas concepciones, profecías, seres y tierras que siendo propias será posible a medida de ir alcanzando la topía de la plenitud, escapándonos así de lo quimérico. 


\section{BIBLIOGRAFÍA Y FUENTES DE CONSULTA:}

ANDRADE, Ma. Cecilia; CÁCERES, Milton; VÁSQUEZ Alexandra. Cosmovisión andina, Sumak Alli Kausay y Economía Comunitaria en "Diálogos sobre Economía Social y Solidaria en Ecuador. Encuentros y desencuentros con las propuestas para otra economía, Instituto Hegoa, Universidad del País Vasco/Euskal Herriko Unibertsitatea, Bilbao, 2014.

ANDRADE, Ma. Cecilia; CÁCERES, Milton. HACIA UN NUEVO MOVIMIENTO CAMPESINO: Nuevos Paradigmas para las luchas sociales, 2006 Serie Pensamiento Alternativo, Fupocps, Quito-2006.

ANDRADE, María Cecilia. La Interculturalidad como Fundamento y Desafío de una experiencia Universitaria, Tesis de Maestría, Cuenca, 2004.

BENAVENTE, Sonia y CLAVERÍAS, Ricardo. Cultura, Educación Desarrollo Rural Andinos, Cosmovisión Andina y Saber Occidental: Hacia una renovación de las ciencias humanas en Indoamérica, Escuela de Educación y Cultura Andina-UEB, 1992, Guaranda- Ecuador.

CÁCERES, Milton. El Gran Poder de la Palabra Desarrollo, Tesis de Diplomado de Estudios Avanzados en Historia de América Latina, Universidad Pablo de Olavide, Sevilla, 2003.

CÁCERES Milton. Entre el Desarrollo y el Buen Vivir: el Espejo Roto y el Llamado, Cuenca, 2011. Publicado en los Anales de la Reunión Anual Etnología. No. 24. La Paz. 23 Mayo, 2012. 
CLASTRES, Hélene. "La Tierra Sin Mal: El profetismo tupiguaraní, Ediciones del Sol Buenos Aires 1989.

ESTERMANN, Josef. "Filosofía Andina: Sabiduría indígena para un mundo nuevo", Colección Teología y Filosofía Andinas. La Paz-Bolivia 2006.

HUANACUNI, Fernando. Buen Vivir / Vivir Bien Filosofía, políticas, estrategias y experiencias regionales andinas [en línea]. Coordinadora Andina de Organizaciones Indígenas - CAO. 2010 [ref. de 28 de febrero]. Disponible en www.minkandina.org.

TEMPLE, Dominique. "Teoría de la Reciprocidad" La Reciprocidad y el Nacimiento de los Valores Humanos, PADEP, La Paz- Bolivia 2003. 